\title{
Assessment Aspects in the Master of Second Level in Foreign Language Teaching
}

\author{
Dr. Ledia Kashahu (Xhelilaj) \\ "Aleksander Moisiu" University, Faculty of Education, \\ Department of Pedagogy Lecturer \\ email:kashahuledia@yahoo.com
}

\section{Doi:10.5901/jesr.2014.v4n2p245}

Abstract

The purpose of this study is to investigate the effect of assessment practices in students' final grade in the course Teaching Methodology, a subject in the Master of Second Level (MSL) program in foreign language teaching in the Faculty of Foreign Languages at Tirana University, more specifically in English and Italian branch $(N=247)$. The sample was chosen based on convenience. In order to judge on the impact of: lecture attendance, seminar attendance, portfolio assignments, course assignment and final examination, was kept rigorous evidence of the points collected from students for each of the above aspects of assessment throughout the first semester of the academic year 2010-2011. By processing and analyzing the data, it resulted that from the statistical point of view, these assessment components exhibit significant positive relationship with the final grade in this subject, namely: lecture attendance (.53), seminar attendance (.72), portfolio assignments (.72), course assignment (.67) and final exam (.70). Likewise, these variables positively predict the final grade of the course. In particular, lecture attendance $(R 2=21.2 \%)$, and the course assignment $(R 2=9.1 \%)$ proved to be predictive of the final grade. Furthermore, portfolio assessment (R2 = $9.7 \%$ ) affects positively the final achievements because it is a way of inviting students to learn systematically and practically and an opportunity for the lecturer to assess students based on their output.

Keywords: students' assessment, assessment techniques, portfolio assignments, students' autonomy, students output

\section{Introduction}

Only if we expand and reformulate our view of what counts as human intellect will we be able to devise more appropriate ways of assessing it and more effective ways of educating it. Howard Gardner ${ }^{1}$

Education in Albania has undergone many changes over the last two decades. In our country, as in many developed countries constructivist models are gaining ground and are facing the traditional methods of transmitting information. Constructivism is a theory that explains how people learn (Musai, 2005). This theory has attracted considerable attention in the field of education, as it is considered a natural, relevant and effective way of learning. The term constructivism is quoted by Marlowe and Page (2005, p. 7) as: a) a process and result of questions, interpretation and analyses of information; b) the use the information to develop thinking, understanding concepts and ideas through their construction; c) combination of current experiences with previous ones and what we know about the subject.

Although constructivism is regarded as a theory of teaching and learning, it has its impact on student evaluation as well. My study focuses on several aspects of constructivist assessment. The constructivist learning goal is to build understanding by developing critical thinking skills and not by learning facts by heart. In a constructivist auditorium the purpose of assessment is to help the lecturer understand the level of students' mastery of concepts and skills when students' progress is monitored throughout the process of teaching. For this reason, assessment of student progress in audiences where is used a teaching methodology based on constructivism, requires the development of a range of assessment techniques in order to enable thinking and knowledge building rather than evaluate the student at the end using a standardized test where the later will demonstrate what is the level of factual knowledge learned. (Biggs \& Tang, 2007).

Jonassen (1991, p . 28-33) presents ten points associated with accurate assessment in the constructivist theory:

${ }^{1}$ Cited from Davies, A.; Le Mahieu, P. Assessment for learning: reconsidering portfolios and research evidence. In M. Segers, F. Dochy; E. Cascaller (Eds.), Innovation and Change in Professional Education: Optimising Neë Modes of Assessment: In Search of Qualities and Standards (p. 141-169). Dordrecht: Kluëer Academic Publishers. Page 1. 
1. Technology will advance the constructivist issue.

2. Student's evaluation will need to be based on the score and have the student at the center.

3. Assessment techniques should be developed in order to reflect learning outcomes.

4. "Grades" should be used only when they are needed.

5. Portfolio assignments should be available.

6. Self-assessment and peer-assessment should be used as well as the assessment by the instructor.

7. Performance standards should be developed.

8. The assessment system should be developed in a way that can provide meaningful information

9. Students should record and collect their work as part of their portfolio.

10. The focus should be on the originality rather than on the repair, as it is important to assess learning by constructing knowledge rather than focusing on the product.

However, we should not forget that it is essential to identify meaningful, acceptable and clear criteria for building knowledge.

\section{Active Participation in the Learning Process}

One of the characteristics of constructivist learning is collaborative learning. Learning in this way not only reinforces social skills that prospective teachers really need, but at the same time maximizes the opportunity to learn as a result of using synergy (Musai, 2008). Working time in the auditorium is very precious and should be appreciated as such. In the teaching methodology of this course was programmed the use of group work and other interactive learning techniques. For this reason in this study practice special attention was given not only to active seminar attendance (a tradition in our university system where seminar attendance is considered more important than lecture attendance) but also to lecture attendance.

\section{Portfolio Assessment}

One of the techniques used in the continuous assessment of students, that is based on the theory of "learning by doing" is Portfolio assessment. This assessment technique is a process that combines reflection and documentation of learning (Musai, 2003). Portfolio assignments help students to be engaged in a continuous reflective and collaborative analysis of learning. It focuses on results that aim to improve not only learning, but also the assessment of learning. The portfolio, enables the documented evaluation of course objectives, gaining experience in applying the knowledge acquired, making the student independent, giving him/her the opportunity to take over the responsibility for his/her learning, developing creative skills and preparing him /her for a future career (Zubizarreta, 2004).

On the other hand, in order to be truly effective, this assessment technique requires a detailed academic planning from the instructor that has to be done in advance. We can mention here the planning for the assignments that will be included in the portfolio based on the objectives that are expected to be fulfilled by each assignment, the time for the realization of outputs, the format type, the method of work, the criteria for assessing each of them, as well as the assessment weight not only of one assignment but of the portfolio as a whole in the final assessment (Biggs \& Tang, 2011).

Portfolio assessment also known as learning portfolio can be used in almost all disciplines, bearing in mind that it should be modeled to suit the needs of different outputs and different formats (Zubizarreta, 2004).

\section{Course Assignment}

Course assignment is primarily conceived as a summary of the skills and abilities acquired by the student during the course. It aims to encourage the student not only to implement the knowledge obtained, but above all to reason and structure creatively and to be able to transfer information. (Biggs \& Tang, 2007)

\section{The Purpose of the Study}

The purpose of this study is: a) to investigate the relationship that exists between variables such as: lecture attendance, seminar attendance, portfolio assignments, course assignment and final grade; b) the impact (weight) of the following variables: lecture attendance, seminar attendance, portfolio assignments and course assignment, in the final exam score 
and in the final grade.

\section{Methodology}

\subsection{Sample}

The sample of this study was selected from the first-year students of the Faculty of Foreign Languages attending the Master of Second Level in foreign language teaching. They were students of English and Italian branch $(\mathrm{N}=247)$ that were selected based on convenience. The subject selected for the realization of the study was 'Teaching methodology'. This course consists of two modules, namely: Critical Thinking and Teaching Methodology. This is a course with a specific practical character, where students are expected to acquire the skills and abilities that will help them to enhance their performance as future teachers, preparing them for effective teaching. In order to judge on the impact of some assessment forms such as: lecture attendance, seminar attendance, portfolio assignments and course assignment, was kept rigorous evidence of the points students had taken in each of the above aspects for 8 groups in total. 5 groups belonged to the English language branch $(N=169)$ and 3 groups to the Italian one $(N=78)$. In total $N=247$ out of which $85 \%$ were female ( $\mathrm{f} / 211)$ and $14 \%$ male $(\mathrm{m} / 36)$.

The study was conducted during the period November - March of the academic year $2010-2011$.

\subsection{Assessment Procedure and Data Collection}

The method of assessing students throughout the semester was programmed in advance, based on the six levels of knowledge in Bloom's taxonomy (Bloom, 1956) as you can see further on:

Table 1. The weight for each assessment component

\begin{tabular}{|c|c|c|c|c|c|c|c|}
\hline \multirow{2}{*}{ Type of assessment } & \multirow{2}{*}{ Percentages \% } & \multicolumn{6}{|c|}{ The level of knowledge, skills and abilities } \\
\hline & & N1 & N 2 & N 3 & N 4 & N5 & N 6 \\
\hline Active participation in lectures ${ }^{2}$ & $10 \%$ & $\sqrt{ }$ & $\sqrt{ }$ & $\sqrt{ }$ & $\sqrt{ }$ & & \\
\hline Active participation in seminars ${ }^{3}$ & $10 \%$ & & $\sqrt{ }$ & $\sqrt{ }$ & $\sqrt{ }$ & $\sqrt{ }$ & \\
\hline Portfolio & $20 \%$ & & & $\sqrt{ }$ & $\sqrt{ }$ & $\sqrt{ }$ & $\sqrt{ }$ \\
\hline Course assignment & $10 \%$ & & & $\sqrt{ }$ & $\sqrt{ }$ & $\sqrt{ }$ & $\sqrt{ }$ \\
\hline Final exam & $50 \%$ & $\sqrt{ }$ & $\sqrt{ }$ & $\sqrt{ }$ & $\sqrt{ }$ & $\sqrt{ }$ & $\sqrt{ }$ \\
\hline
\end{tabular}

\subsection{Lecture and Seminar Attendance}

Lecture attendance was given 0.16 points for every class attended, since students had to attend 60 seminar classes throughout the 15 weeks. Seminar attendance was given 0.33 points for every class attended, since students had to attend 30 seminar classes throughout the 15 weeks.

\subsection{Portfolio Asessment}

Furthermore, the content of the assignments that would be part of the portfolio was programmed based on course objectives. The students had to hand in10 assignments based on the topics that would be covered during 15 weeks. On the first page of the portfolio were attached the course objectives and for each assignment that was completed the students had to mark the course objectives that it met.

The portfolio is completed with the instructor's assessment at the end of the semester (before the exam students are acquainted with the portfolio assessment).

\footnotetext{
${ }^{2}$ In the course has also been included group work not only to practise teaching methods, but also to practise critical thinking skills during the lecture. Thus we are not talking only about mere participation, but for group work in which each student has a role and a personal responsibility in front of the group.

${ }^{3}$ In the course has also been included group work not only to practise teaching methods, but also to practise critical thinking skills during the seminar. Thus we are not talking only about mere participation, but for group work in which each student has a role and a personal responsibility in front of the group.
} 


\subsection{Course Assignment Assessment}

For the course assignment were followed these evaluation criteria:

- For the correct formulation of objectives of a lesson and for making up no less than three questions that develop critical thinking, 2 points.

- For building the structure of a lesson, 2 points.

- For the logical reasoning of the structure that was built, 2 points.

- For reasoning related to critical thinking skills that the student can develop in this class based on a text chosen by the student himself, 2 points.

- $\quad$ For the coherence between the objectives, methods selected in the structure and methods of assessment, 2 points.

\subsection{For the Final Exam}

The final exam had a total of 50 points which were divided proportionally according to the modules as follows:

Table 2. Number of questions and points according to the levels of thinking

\begin{tabular}{|c|c|c|c|c|c|c|c|c|}
\hline & \multirow{2}{*}{$\begin{array}{c}\text { Weight in } \\
\text { assessment }\end{array}$} & \multirow{2}{*}{$\begin{array}{l}\mathrm{Nr} \text {. of questions } \\
\text { and points }\end{array}$} & \multicolumn{6}{|c|}{ The levels of knowledge, skills and abilities } \\
\hline & & & N 1 & N2 & N3 & $\mathrm{N} 4$ & N5 & $\mathrm{N} 6$ \\
\hline \multirow{3}{*}{ Module: Methodology } & \multirow{3}{*}{$50 \%$} & q $110 p$ & & & $\sqrt{ }$ & $\sqrt{ }$ & & \\
\hline & & $q 25 p$ & $\sqrt{ }$ & $\sqrt{ }$ & $\sqrt{ }$ & & & \\
\hline & & q $310 p$ & & & $\sqrt{ }$ & $\sqrt{ }$ & $\sqrt{ }$ & $\sqrt{ }$ \\
\hline \multirow{3}{*}{ Module: Critical thinking } & \multirow{3}{*}{$50 \%$} & $q 15 p$ & & $\sqrt{ }$ & $\sqrt{ }$ & $\sqrt{ }$ & & \\
\hline & & $q 210 p$ & & & $\sqrt{ }$ & $\sqrt{ }$ & $\sqrt{ }$ & \\
\hline & & q $310 p$ & & & & $\sqrt{ }$ & $\sqrt{ }$ & $\sqrt{ }$ \\
\hline
\end{tabular}

\subsection{Analysis of Data}

The data collected throughout the first semester for each of the variables planned for assessing students, were processed with the SPSS statistical program. For the analysis of data were used elements of descriptive and inferential statistics. For all the cases of assessment variables (lecture attendance, seminar attendance, portfolio assignments, course assignment, final grade) scores were grouped into five categories of unrepeatable intervals. To determine the relationship between the assessment components; lecture attendance, seminar attendance, portfolio assignments, course assignment, final exam with the final grade, cross tabulations were used. To determine the strength of the relationship between assessment components, achievement in the final exam and final grade were used correlation coefficients by Davis ${ }^{4}$ (1971). Whereas to determine the impact of assessment components in the final exam score but also in the final grade of the course Teaching methodology and Critical Thinking, regression analyzes were performed using Enter method. In this paper are reported those results that were statistically reliable.

\section{Results}

\subsection{Assessment Variables and the Final Exam in this Course}

\subsubsection{Participation in the Lecture}

Descriptive analysis of cross tabulation showed that there was a relationship between students' academic achievement and the assessment variable of lecture attendance, which means that students who have managed to collect points as a result of active participation in lectures, have had a better final mark compared to the other students who have not participated actively in lectures. More specifically, students who have not attended lectures have had lower scores. 62.5

\footnotetext{
${ }^{4}$ The meaning of values of the correlation coefficient according to Davis (1971) is: .70 and higher indicates very strong correlation; .50 .69 indicates substantial connection (significant); .30 - .49 indicates a moderate correlation (average); .10 - .29 shows a weak correlation; .00 - .09 shows insignificant correlation.
} 
$\%$ of the failing students, belong to those who have not attended the lectures at all. Out of 27 students with poor attendance of lectures, $22.2 \%$ have failed the course, $14.8 \%$ scored 'poor' and $14.8 \%$ scored 'good'. Out of the 39 students with a sufficient attendance of lectures, $12.8 \%$ have failed, $5.1 \%$ scored 'poor', and $25.6 \%$ scored 'good'. Out of 92 students with good attendance of lectures, $30.4 \%$ of them scored 'excellent' $50 \%$ scored 'very good' and $13 \%$ scored 'good'. Only $2.2 \%$ of students with good attendance have failed the course. Out of 79 students with good attendance of lectures $48.1 \%$ scored 'excellent', $41 \%$ scored 'very good' and $6.3 \%$ scored 'good'. We notice there are not any failing students. Graph 1 clarifies the results analyzed above.

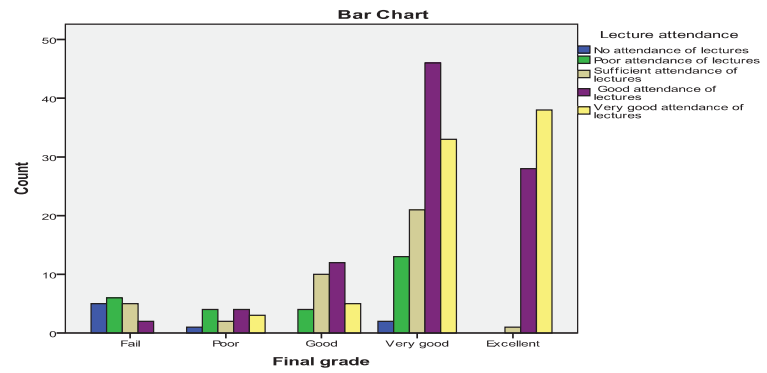

Graph 1. Lecture attendance and the final grade

\subsubsection{Seminar Attendance}

The descriptive analysis of cross tabulation between seminar attendance variable and final course grade variable indicated that the final achievement expressed in the form of the grade has a very positive relationship with the frequency of seminar attendance by students. As you can see from data analysis, all students who have not attended seminars have failed; the same was true for $75 \%$ of students with poor seminar attendance, also for $25 \%$ of students with a sufficient seminar attendance. Concerning the students with a very good attendance in seminars it was noticed that they also have scored 'very good' in the final assessmnet. For example; $52.1 \%$ of students scored 'very good' and $28.8 \%$ scored 'good'. For more see Chart 2.

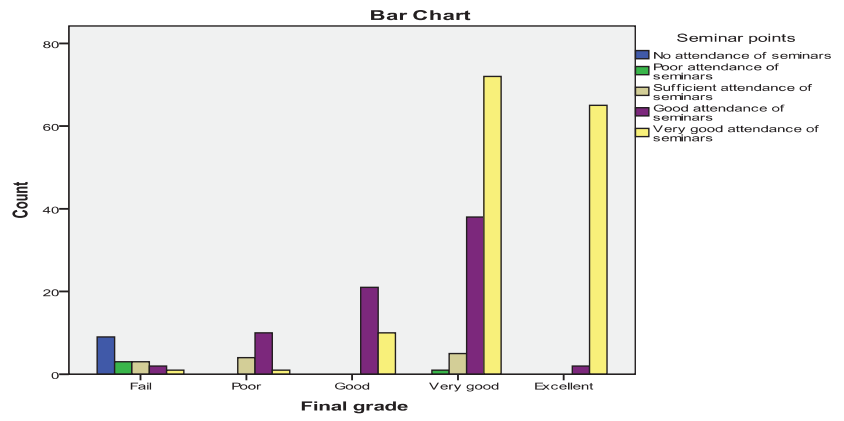

Graph 2. Seminar attendance and the final grade

\subsection{Portfolio Assignments}

Descriptive analysis of cross tabulation through frequency and percentages indicated that there is a positive relationship between the students' points from portfolio assignments and final assessment with a grade. If it is compared with the variable of seminar attendance, it becomes clear from the frequencies and percentages that the accumulation of more points in portfolio assignments, results in higher scores in students grades.

The data showed that $84 \%$ of students that failed the course had no assignment in their portfolio. Whereas out of the students who had done very well in portfolio assignments, $38.8 \%$ have achieved 'excellent' in the final grade, and 51 $\%$ have achieved 'very good'. Out of students who had done well in portfolio assignments, $52.4 \%$ have achieved 'very good' in the final grade and $33.3 \%$ have achieved 'good'. A clearer perspective of these results can be seen in graph 3 . 


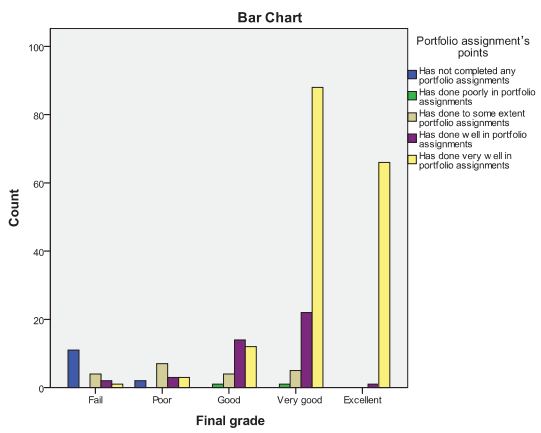

Graph 3. Students' points from portfolio assignments and the final grade

\subsection{Course Assignment}

From the statistical analysis was noticed a positive relationship between the students' points in the course assignment and the final result expressed in grade. From frequencies and percentages obtained by the cross tabulation of these two variables we can say that out of 55 students who have handed in no course assignment, $29 \%$ have failed the course, 20 $\%$ scored 'sufficient', $25 \%$ scored 'good', $25 \%$ scored 'very well', and there was no student who scored 'excellent'. On the other hand, out of the students who have done very well in the course assignment, $45.8 \%$ scored 'excellent' even in the final assessment, and $49.4 \%$ scored 'very good'. Out of students who have done well in the course assignment, 27.8 $\%$ have scored 'excellent' in the final assessment and $58.9 \%$ of them have scored 'very good'.

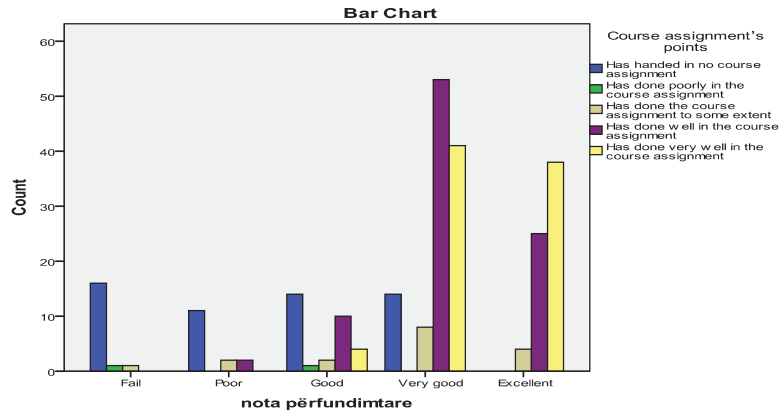

Graph 4. Course assignment's points and the final grade

Descriptive analysis showed that nearly one in four students have managed to score 'excellent' and almost one in two students have managed to score 'very well'. Thus, nearly three-quarters of the students have achieved high scores. Only $7.29 \%$ of students have failed the course. This satisfactory result that was achieved is related to the advance planning of the course, but also to the assessment criteria that was communicated to students at the beginning of the course.

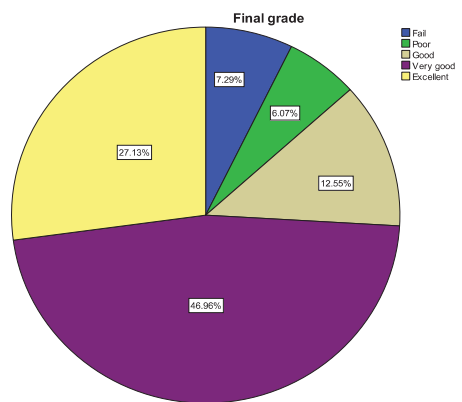

Graph 5. Distribution of values according to students' results in the final grades 
In order to study the strength of relationships between assessment and achievement variables in the final exam and the final grade of the course were conducted correlation analyzes between these variables. The data showed the existence of positive relationships in all the cases. The assessment components showed weak to moderate correlation to the final exam and a stronger correlation (from substantial to strong) to the final grade. More specifically, the analysis showed a weak correlation between final exam and lecture attendance $(r=0.24)$ as well as between final exam points and portfolio assessment $(r=0.23)$, but they were statistically significant. Furthermore, the correlation between the final grade and lecture attendance was substantial $(r=0.53)$ whereas the correlation between final exam points and portfolio assessment resulted strong $(r=0.23)$.

The final grade resulted to have moderate correlation with seminar attendance $(r=0.30)$ and course assignment $(r$ $=0: 32)$ meanwhile the relationship resulted to be strong between the final grade and seminar attendance $(r=0.72)$ and substantial between the final grade and course assignment $(r=0.67)$.

Table 3. The relationship between the assessment criteria, final exam points and final grade

\begin{tabular}{rlcc}
\hline \multicolumn{2}{c}{ The assessment variables } & Final exam points & Final grade \\
\hline 1. & Lecture attendance & $0.24^{\star}$ & $0.53^{\star \star}$ \\
2. & Seminar points & $0.30^{\star}$ & $0.72^{\star \star \star}$ \\
3. & Portfolio assignment's points & $0.23^{\star}$ & $0.72^{\star \star \star}$ \\
4. & Course assignment's points & $0.32^{\star}$ & $0.67^{\star \star \star}$ \\
5. & Final exam points & $0.70^{\star \star \star}$ \\
\hline & Note: ${ }^{\star} p<0,05 .{ }^{\star \star} p<0,01 .{ }^{* \star \star} p<0,001$ &
\end{tabular}

To study the influence of the following variables: lecture attendance, seminar attendance, portfolio assignments and course assignment in the final exam points 4 regression analyzes were conducted using the Enter method. In the first block was included lecture attendance ( 1 = lecture attendance), in the second block was included seminar attendance (2 = seminar attendance), in the third block was included portfolio assignments ( $3=$ portfolio assignments), and in the fourth one, the course assignment ( $4=$ course assignment). The data processing showed that lecture attendance positively affects the final exam points $\beta=22, t=15.05, p<.001, R 2=28 \%, \beta$ seminar points $=19, t=3: 06, p<.01, R 2=26$ $\%$, portfolio assignments points $\beta=29, t=5: 02, p<.001, R 2=7.2 \%$, course assignment points $\beta=35, t=7.74, p$ $<.001, \mathrm{R} 2=7.7 \%$.

Table 4. Regression analysis to predict the final exam points from the other assessment components

\begin{tabular}{lccc}
\cline { 2 - 4 } Predicting variables & \multicolumn{2}{c}{} & $\mathrm{t}$ \\
\hline 1. Lecture attendance & $\beta$ & $.22^{\star \star \star}$ & 5.15 \\
2. Seminar points & $.19^{\star \star}$ & 3.06 \\
3. Portfolio assignment's points & $.29^{\star \star \star}$ & 5.02 \\
4. Course assignment's points & $.35^{\star \star \star}$ & 7.74 \\
\hline
\end{tabular}
Note: " $p<0,05$. " $p<0,01$. "** $p<0,001$.

To study the influence of the following variables: lecture attendance, seminar attendance, portfolio assignments, course assignment and final exam points in the final grade a total of 5 regression analyzes were conducted using the Enter method. In the first block was included lecture attendance ( $1=$ lecture attendance), in the second block was included seminar attendance $(2=$ seminar attendance), in the third block was included portfolio assignments $(3=$ portfolio assignments), in the fourth block was included the course assignment ( $4=$ course assignment) and in the fifth one, the final exam points ( $5=$ final exam points). It was found that lecture attendance affects positively the course final grade $\beta=$ $16, t=5.35 p<.001, R 2=21.2 \%$, the points from the portfolio assignments $\beta=32, t=8.82 p<.001, R 2=9.7 \%$, the points from the course assignment $\beta=25, t=7.7, p<.001, R^{2}=9.1 \%$ and the final exam points $\beta=50, t=17.92$, $p<.001, R^{2}=21.2$. 
Table 5. Regression analysis to predict the final grade from the other assessment components

\begin{tabular}{lll}
\hline & \multicolumn{2}{c}{ Final exam points } \\
\hline Predicting variables & $\beta$ & $\mathrm{t}$ \\
\hline 1. Lecture attendance & $.16^{\star \star \star}$ & 5.35 \\
2. Seminar points & .07 & 1.85 \\
3. Portfolio assignment's points & $.32^{\star \star \star}$ & 8.82 \\
4. Course assignment's points & $.25^{\star \star \star}$ & 7.7 \\
5. Final exam points & $.50^{\star \star \star}$ & 17.92 \\
\hline \multicolumn{1}{c}{ Note: ${ }^{*} p<0,05 .{ }^{*} p<0,01 .{ }^{* * *} p<0,001}$. & &
\end{tabular}

\section{Discussion}

Based on the findings it results that assessment is an activity that must be addressed and planned very carefully. Every detail of assessment must be planned carefully since the beginning of the course so that everything is measured correctly enabling not only the achievement of course academic objectives but also the maximization of each student's learning. As expressed by Halpern (2003, p 38) "We should always keep in mind that we are lecturing for the future, when we will not be present - and we are preparing our students to analyze the real world that is unpredictable and not simply for the traditional final exams."

In this study, the assessment of student achievement was planned by using five different assessment variables so that knowledge, skills and competences planned in the course objectives could be achieved at a high level by most of the students. Results showed that three-quarters of the students achieved high scores in the course final assessment, which was expressed in grade. Only a small percentage of students failed the course. Researchers who are dedicated to the study of qualitative teaching have concluded that the use of as many variables in assessing students increases the chances to improve the quality of learning but also the possibility of being as near as possible to a fair assessment of students (Biggs and Tang 2011).

The study also found that the achievement of students in the final examination, which was a summary of all the knowledge, skills and abilities planned, where the questions were categorized and designed according to the levels of thinking in Bloom taxonomy ( 1956) correlates positively with variables planned for student assessment, starting from weak correlations with lecture attendance and portfolio assignments to moderate correlations with variables like seminars attendance and course assignment. Regarding the correlation of the above assessment variables with the final grade of the course it was noticed that the strength of their relationship varied from substantial for lecture attendance and course assignment to strong correlation in the case of seminar attendance, portfolio assignments and final exam. It means that the more students attend auditoriums and the more they try to meet obligations as in the case of portfolio assignments and course assignment, the higher will be their achievements in the final exam as well as in the final course grade.

Findings from the analysis of cross tabulation clarified in more detail some facts relating to the assessment variables taken into consideration in this study such as: $62.5 \%$ of the students that failed, had not attended lectures. Similarly, $22 \%$ of the students scored 'poor'. On the other hand, $48.1 \%$ of students with a very good attendance of lectures have scored 'excellent'.

Seminar attendance also resulted significant and positively associated with students' final achievement. For example, all the students who have not attended seminars have failed the course, the same can be said about $75 \%$ of students with a poor attendance of seminars whereas $52.1 \%$ of students who scored 'excellent' had a very good attendance of seminars. It is important to take into consideration the fact that during the seminars were discussed various issues of literature and group work was used to meet the course objectives. Also, students consulted the lecturer and their peers about the assignments that would be part of the portfolio. This has enabled students to exchange their experiences, to make a critical analysis of their work, which was followed by student reflection on the improvement of their output.

Portfolio assignment resulted to have a significant and positive relationship with the final grade. More specifically $84 \%$ of students who failed to take the course had not handed in any assignment for their portfolio whereas $85.7 \%$ of students who had done 'well' and 'very well' in portfolio assignments, have also scored 'excellent' in the final assessment. These results show the importance of the students' work throughout the semester, with the aim to realize their output in the portfolio and the impact that these outputs have had in their final results expressed in grade. While concerning course assignment, $29 \%$ of students who had handed in no course assignment resulted to have failed the course. Also students who had done 'very well' in the course assignment constitute $49.4 \%$ of students who scored 'very 
good' in the final assessment.

The impact of these assessment variables is significant in predicting the final grade of the course, particularly, lecture attendance $\left(R^{2}=21.2 \%\right)$. Furthermore, portfolio assessment $\left(R^{2}=9.7 \%\right)$ and course assignment $\left(R^{2}=9.1 \%\right)$ proved to be predictive of the final grade. In pedagogical practice at universities, special attention is paid to active participation. In all study programs is clearly specified the necessity of students' attendance in the lesson process by setting the threshold of absences up to $25 \%$. The same importance is given to course assignment, which in many programs constitutes a requirement for students' admission in the final exam. More specifically, this paper has tried to point out the weight and importance of the organization of assessment forms, such as portfolio assignments, which is not often encountered in assessment practices Bachelor programs, Master of First Level programs or Master of second Level programs. Portfolio assignments affect positively the final achievement, since it is a way of inviting students to learn systematically and practically as well and an opportunity for the lecturers to assess students based on their products. One of the reasons of portfolio assignments impact can also be the students' continuous metacognition in their work with the portfolio, which helps them to define more clearly what they have learned and what they still do not know or cannot do properly concerning their progress in the relevant field.

\section{Conclusions}

Students' achievements in a particular course are associated with many factors, some of which are not up to the instructor, but the way the course is planned, forms of teaching and techniques selected for their evaluation and their clarification for the students at the beginning of the course increase students' chance of success. The study revealed that portfolio assignments have a significant impact on students' academic achievements and this empirical evidence may serve to recommendto instructors at university level to use this technique for assessing students. Even the researchers Biggs and Tang (2011) estimate that portfolio assignments constitutes a great opportunity to help students become more systematic in their learning, to take more responsibility for their progress, to enable them understand their strengths and weaknesses, to help them define the challenges and the work they must do in the future in order to minimize weaknesses, and most importantly, continuous research enables their increase of autonomy in learning.

In Albania, to the author's knowledge, there have been conducted no studies of the quantitative aspect related to the assessment components of teaching in universities. Even in the world literature such studies are very rare. Data from this study will be useful for students to create a clear idea of the work ahead, enabling them to predict results based on empirical data, but also to their lecturers who based on these findings will be more careful in the assessment of each variable they will use for student's evaluation. This study, however, has several limitations. Firstly, the sample was selected based on the researcher opportunities for realizing the aims of the study. For that reason we would recommend similar studies conducted methodologically. Secondly, being peculiar from the methodological point of view, the findings of this study cannot be compared with previous studies in the field of assessment of student achievements.

\section{Literatura}

Biggs, J and Tang C. (2011). Teaching for Quality Learning at University, McGraw-Hill and Open University Press, Maidenhead 255-287 Biggs, J. \& Tang, C. (2007) Teaching for Quality Learning at University Maidenhead: Open University Press/McGraw Hill.

Bloom, B. S. (1956). Taxonomy of Educational Objectives, Handbook I: The Cognitive Domain. New York: David McKay Co Inc. Halpern, D. F. (2003) To the University and Beyond: Teaching for Long-Term Retention and Transfer Change, pp. 37-41 Jonassen, D. H. (1991) Evaluating constructivistic learning në Educational Technology, nr. 31, pp 28-33.

Marlowe, B. A.; \& Page, M. L. (2005). Creating and sustaining the constructivist classroom (Second Edition). California: Corwin Press, Musai., B. (2003) Metodologji e mësimdhënies, PEGI, Tiranë

Musai., B. (2005) Mësimdhënia dhe te nxënit ndërveprues në shkencat shoqërore. Botim "CDE"Tiranë

Musai., B. (2008). Modele dhe metoda të mësimdhënies bashkëkohore. Cikël leksionesh të pa botuara.

Zubizarreta, J. (2004). The Learning Portfolio: Reflective Practice for Improving Student Learning. Boston, Mass.: Anker 